\title{
Ocular Response Analyzer to Assess Age-Related Biomechanical Characteristics of the Cornea in a Taiwanese Population
}

\author{
Tsung-Jen Wang1,2,3,4, Shwu-Huey Lee5, Wen-Jing Hsu5, David Chao-Kai Chang6, \\ I-Jong Wang3,4* \\ ${ }^{1}$ Department of Ophthalmology, Taipei Medical University Hospital, Taipei, Taiwan \\ ${ }^{2}$ Department of Ophthalmology, School of Medicine, College of Medicine, Taipei Medical University, \\ Taipei, Taiwan \\ ${ }^{3}$ College of Medicine, National Taiwan University, Taipei, Taiwan \\ ${ }^{4}$ Department of Ophthalmology, National Taiwan University Hospital, Taipei, Taiwan \\ ${ }^{5}$ Department of Ophthalmology, Cathay General Hospital, Taipei, Taiwan \\ ${ }^{6}$ Nobel Eye Clinic, Taipei, Taiwan \\ Email: tjw.tw@msa.hinet.net
}

Received 21 March 2014; revised 20 April 2014; accepted 19 May 2014

Copyright (C) 2014 by authors and Scientific Research Publishing Inc.

This work is licensed under the Creative Commons Attribution International License (CC BY).

http://creativecommons.org/licenses/by/4.0/

(c) (i) Open Access

\begin{abstract}
Purpose: To investigate biomechanical properties of the cornea as measured using a Reichert ocular response analyzer (ORA) in a Taiwanese population. Methods: Basic demographic data were recorded for 1875 Taiwanese subjects. Corneal hysteresis (CH), corneal resistance factor (CRF), central corneal thickness (CCT), Goldmann-equivalent intraocular pressure (IOPg), and corneal-compensated intraocular pressure (IOPcc) were measured with an ORA. Descriptive statistics and multiple regression analyses were used to assess and compare relevant factors of the CRF and CH. Results: In total, 1817 eyes were included in this study. The mean patient age was $21.4 \pm 17.01$ years. The mean $( \pm S D) C H$ and $C R F$ values were $10.6 \pm 1.81$ and $10.6 \pm 1.99 \mathrm{mmHg}$, respectively. The mean CCT was $560.4 \pm 38.53 \mu \mathrm{m}$. CH was correlated with IOPcc, CRF, and CCT. In the multiple linear-regression model, $\mathrm{CH}$ was associated with and affected by IOPcc, CRF, and CCT. In another multiple linear-regression model, CRF was associated with and affected by IOPcc, $\mathrm{CH}$, and CCT. Conclusions: Measuring biomechanical properties by Reichert ORA, we found that $\mathrm{CH}$ and CRF values of a Taiwanese population were similar to those other Asian populations and other races. Our findings provided fundamental data of $\mathrm{CH}$ and $\mathrm{CRF}$ in a Taiwanese (ethic Chinese) and also Asian population.
\end{abstract}

${ }^{*}$ Corresponding author.

How to cite this paper: Wang, T.-J., Lee, S.-H., Hsu, W.-J., Chang, D.C.-K. and Wang, I-J. (2014) Ocular Response Analyzer to Assess Age-Related Biomechanical Characteristics of the Cornea in a Taiwanese Population. International Journal of Clinical Medicine, 5, 650-656. http://dx.doi.org/10.4236/ijcm.2014.512089 


\section{Keywords}

\section{Corneal Hysteresis (CH), Corneal Resistance Factor (CRF), Central Corneal Thickness (CCT)}

\section{Introduction}

The cornea possesses both stiffness and viscoelasticity properties. Hysteresis is a parameter to describe the biomechanical properties of the cornea [1]. There was no method to determine the corneal biomechanical properties until the use of Reichart ocular response analyzer (ORA) [2]. Both corneal hysteresis (CH) and corneal resistance factor (CRF) are derived using the Reichart ORA, and they were proposed as indicators of corneal biomechanical properties [3] [4]. The device utilizes a brief air impulse to rapidly deform the cornea and monitors the shape of the cornea during deformation by an advanced electro-optical system. The inward and outward applanations induced by the air puff are measured. The two different pressures are averaged to provide the non-contact tonometer intraocular pressure (IOPg). The difference between the two pressures caused by the inward and outward applanation is referred to as $\mathrm{CH}$.

In addition, during the same bidirectional process, corneal resistance factor (CRF) and corneal-compensated intraocular pressure (IOPcc) are also derived by ORA software [5]. CRF was suggested to serve as an indicator of the overall corneal resistance encountered during the measurement process which is related to $\mathrm{CH}$ and central corneal thickness (CCT). The IOPcc is a pressure measurement that uses new information provided by $\mathrm{CH}$, and the manufacturer claims that it is less affected by corneal properties.

The primary purpose of this study was to investigate the aging effect on biomechanical characteristics of the cornea in a Taiwanese population. Previous work suggested that biomechanical properties of the cornea decrease with greater age, and we wanted to determine if differences exist in different populations. The secondary goal was to survey the association of $\mathrm{CH}$ values with both CCT and refractive errors. The final purpose was to assess possible relationships between ORA parameters and age in a healthy Taiwanese (ethnic Chinese) population.

\section{Materials and Methods}

The basic demographic data were recorded in 1875 Taiwanese from January 2006 to July 2009. The study was approved by the institutional review board of Taipei Medical University (Taipei, Taiwan).

$\mathrm{CH}$, CRF, CCT, Goldmann-equivalent intraocular pressure (IOPg), and IOPcc were measured with the ORA. Spherical equivalent (SE) of refraction was also obtained. All measurements were repeated three times for each eye. All Taiwanese (ethnic Chinese) subjects were included. Participants were excluded if they had any previous ocular surgery or corneal diseases such as keratitis, Fuchs' dystrophy, and keratoconus.

$\mathrm{CH}$ was measured by ORA. ORA software utilizes $\mathrm{CH}$ to derive two additional parameters: IOPcc and CRF. IOPg is also provided by the machine. The eyes of all patients were anesthetized with 1 drop of topical $0.5 \%$ Alcaine (proparacaine hydrochloride) before the CCT measurement with a contact ultrasound pachymetry probe included with ORA machine. The probe was placed perpendicular to the midpupillary axis, and the mean of three measurements was recorded. For the purpose of the study, all ocular measurements of the right eye were included in the analysis.

Descriptive statistics and multiple regression analyses were used to assess and compared the relevant factors of $\mathrm{CH}$ and CRF. Multiple linear regression models were constructed with $\mathrm{CH}$ and $\mathrm{CRF}$ as dependent variables and other associated factors as covariates. All statistical analyses were performed using SPSS for Windows, version 16.0 (SPSS, Chicago, IL, USA). A $p$ value of $<0.05$ or 0.01 or 0.001 indicated statistical significance.

\section{Results}

In total, the only right eyes of 1817 subjects were included in the study. The mean patient age was $21.5 \pm 17.24$ (range, 5.27 - 87.8) years, the distribution of the gender was $58.7 \%$ female and $41.3 \%$ male, and all were Taiwanese (ethnic Chinese). Demographic data are shown in Table 1. The mean $( \pm \mathrm{SD}) \mathrm{CH}$ was $10.6 \pm 1.81$ (range, 5.5 - 15.6) $\mathrm{mmHg}$ and CRF was $10.6 \pm 1.99$ (range, 5.1 - 16.2) $\mathrm{mmHg}$. Mean CCT was $560.4 \pm 38.53$ (range, 367 - 711) $\mu \mathrm{m}$. Mean values of SE, IOPg, and IOPcc were $-3.7 \pm 3.21$ (range, $-17.25-8.5$ ) diopter, $15.9 \pm$ 
Table 1. Demographic data, right eyes $(n=1817)$.

\begin{tabular}{cccc}
\hline & Mean \pm SD & Range & 95\% CI \\
\hline Age (years) & $21.4 \pm 17.01$ & $5.27-87.8$ & $20.63-22.21$ \\
IOPg (mmHg) & $15.9 \pm 4.08$ & $5.0-33.6$ & $15.69-16.06$ \\
IOPcc (mmHg) & $16.2 \pm 4.04$ & $5.8-37.8$ & $15.99-16.37$ \\
CRF & $10.6 \pm 1.99$ & $5.1-16.2$ & $10.54-10.73$ \\
CCT & $560.4 \pm 38.53$ & $367.0-711.0$ & $558.49-562.23$ \\
CH & $10.6 \pm 1.81$ & $5.5-15.6$ & $10.47-10.63$ \\
SE (diopters) & $-3.7 \pm 3.21$ & $-17.25-8.5$ & $-3.80-3.50$
\end{tabular}

IOPg, Goldmann-equivalent intraocular pressure; IOPcc, corneal-compensated intraocular pressure; CRF, corneal resistance factor; CCT, central corneal thickness; $\mathrm{CH}$, corneal hysteresis; SE, spherical equivalent.

4.08 (range, 5.0 - 33.6) $\mathrm{mmHg}$, and $16.2 \pm 4.04$ (range, 5.8 - 37.8) $\mathrm{mmHg}$, respectively.

$\mathrm{CH}$ was significantly correlated with CRF (Pearson correlation coefficient $r=0.79, p=0.0039$ ), IOPcc ( $r=$ $-0.47, p=0.0027)$, and CCT $(r=0.39, p=0.0013)$. CH was not correlated with IOPg $(r=0.03, p=0.27)$ or SE $(r=0.04, p=0.09)$. CRF was significantly correlated with IOPg $(r=0.63, p=0.0032)$, IOPcc $(r=0.15, p=$ $0.0017)$, and CCT $(r=0.53, p=0.0023)$, but not correlated with SE $(r=0.04, p=0.13)$. IOPg was significantly correlated with IOPcC $(r=0.86, p=0.0068)$ and CCT $(r=0.40, p=0.0017)$, but not with SE $(r=0.01, p=$ $0.65)$. IOPcc was significantly correlated with CCT $(r=0.15, p=0.0013)$, but not with SE $(r=-0.01, p=0.76)$ (Table 2).

Using multiple linear-regression modeling, we were able to determine the association of $\mathrm{CH}$ and CRF with covariates such as age, gender, IOPcc, CCT, and SE (Table 3, Table 4). The tolerance of the regression was $>0.1$, and the variance inflation factor was $<10$. Therefore, no co-linearity was found for any parameters. $\mathrm{CH}$ was not correlated with age, gender, or SE, but it was significantly associated with and affected by IOPcc, CRF, and CCT. In another multiple linear-regression mode, CRF was associated with and affected by IOPcc, $\mathrm{CH}$, and CCT, but CRF was not correlated with age, gender, or SE. Parameters used in the regression analyses accounted for $>3.4 \%$ of the variance in the multivariate model. Finally, there was a significant correlation between $\mathrm{CH}$ and $\operatorname{CRF}\left(R^{2}=0.61\right.$, Figure 1$)$.

\section{Discussion}

$\mathrm{CH}$ is a measure of corneal biomechanical properties that can be measured with dynamic bidirectional applanation as used in the Reichert ORA. This device uses an impulse produced by a rapid jet of air to deform the cornea and an advanced electro-optical system to monitor the shape of the cornea during deformation. From previous ex vivo studies, it is known that the stiffness of the cornea increases with age. Lim et al. reported that mean CH, CRF, and CCT were $11.78 \mathrm{mmHg}, 11.81 \mathrm{mmHg}$, and $578.67 \mu \mathrm{m}$ in 271 Singaporean children [6]. Kirwan et al. assayed the corneal biomechanical properties in 81 normal eyes of children, and mean $\mathrm{CH}$ was $12.5 \pm 1.35 \mathrm{mmHg}$ [5]. CH values reported in normal adults are generally lower [7]. Shah et al. reported a mean $\mathrm{CH}$ of $10.7 \pm 2.0 \mathrm{mmHg}$ in normal adults, while Kirwan et al. reported $10.8 \pm 1.4 \mathrm{mmHg}$ [4] [5]. Most reports confirmed that $\mathrm{CH}$ varies over a wide range in normal individuals, and the range of measurement we obtained of $5.1-16.2 \mathrm{mmHg}$ is comparable to the widest reported range of $6.1-17.6 \mathrm{mmHg}$. Age-related changes in the corneal biomechanical properties may be explained by changes in corneal collagen fibrils. With an advancing age, the corneal viscoelastic properties may be affected by increases in cross-linkages of collagen fibrils within the cornea. This leads to a stiffer and less-viscoelastic corneal structure [8]. In addition, conditions like Fuchs' dystrophy, keratoconus, and refractive surgery can cause the corneal collagen to have an irregular arrangement resulting in CH alterations [9] [10]. From our survey, the mean $\mathrm{CH}$ was $10.6 \pm 1.81 \mathrm{mmHg}$ with a range of 5.1 $16.2 \mathrm{mmHg}$ which was similar to those in previous studies. Although $\mathrm{CH}$ significantly decreased by aging in the previous similar studies [11] [12], there was no statistical significance in our study. Nevertheless, Lim et al. found $\mathrm{CH}$ not vary with age [6]. Compared to study population from Kamiya and Narayanaswamy [11] [12], the mean age of population, in our and Lim's study was relatively young (21.5 and 13.97, respectively). Further 
Table 2. Pearson's correlations among corneal hysteresis, corneal resistance factor, corneal-compensated intraocular pressure, and central corneal thickness.

\begin{tabular}{|c|c|c|c|c|c|c|}
\hline & CH & CRF & IOPg & IOPcc & CCT & $\mathrm{SE}$ \\
\hline $\mathbf{C H} r$ & 1.00 & 0.79 & 0.03 & -0.47 & 0.39 & 0.04 \\
\hline$p$ & - & $<0.01^{* *}$ & 0.27 & $<0.01^{* *}$ & $<0.01^{* *}$ & 0.09 \\
\hline CRF $r$ & - & 1.00 & 0.63 & 0.15 & 0.53 & 0.04 \\
\hline$p$ & - & - & $<0.01^{* *}$ & $<0.01^{* *}$ & $<0.01^{* *}$ & 0.13 \\
\hline IOPg $r$ & - & - & 1.00 & 0.86 & 0.40 & 0.01 \\
\hline$p$ & - & - & - & $<0.01^{* *}$ & $<0.01^{* *}$ & 0.65 \\
\hline IOPcc $r$ & - & - & - & 1.00 & 0.15 & -0.01 \\
\hline$p$ & - & - & - & - & $<0.01^{* *}$ & 0.76 \\
\hline CCT $r$ & - & - & - & - & 1.00 & -0.02 \\
\hline$p$ & - & - & - & - & - & 0.35 \\
\hline $\mathrm{SE} r$ & - & - & - & - & - & 1.00 \\
\hline$p$ & - & - & - & - & - & - \\
\hline
\end{tabular}

$\mathrm{CH}$, corneal hysteresis; CRF, corneal resistance factor; IOPcc, corneal-compensated intraocular pressure; CCT, central corneal thickness; IOPg, Goldmann-equivalent intraocular pressure; SE, spherical equivalent $\left({ }^{* *} p<0.01\right)$.

Table 3. Multiple linear regression model of the factors associated with corneal hysteresis.

\begin{tabular}{lcccc}
\hline & Unadjusted (95\% CI, $\boldsymbol{n}=\mathbf{1 8 1 7})$ & $p$ & Multivariable-adjusted (95\% CI, $\boldsymbol{n}=\mathbf{1 5 9 1})$ & $p$ \\
\hline Age (years) & $-0.004(-0.01$ to 0.0005$)$ & 0.008 & $-0.0007(-0.002$ to 0.0001$)$ & 0.08 \\
Gender & Reference & & Reference \\
Female & $-0.15(-0.32$ to 0.02$)$ & 0.08 & $-0.03(-0.03$ to 0.03$)$ & $-0.27(-0.27$ to -0.26$)$ \\
Male & $-0.21(-0.23$ to -0.19$)$ & $<0.01^{* *}$ & $0.79(0.79$ to 0.80$)$ & $<0.001^{* * *}$ \\
IOPcc (mmHg) & $0.72(0.69$ to 0.74$)$ & $<0.01^{* *}$ & $0.0004(0.0001$ to 0.0009$)$ & $0.001^{* * *}$ \\
CRF & $0.018(0.015$ to 0.02$)$ & $<0.01^{* *}$ & $0.0029(-0.0016$ to 0.0074$)$ & 0.21 \\
CCT & $0.023(-0.0032$ to 0.048$)$ & 0.09 &
\end{tabular}

$R^{2}=0.974$. CH, corneal hysteresis, IOPcc, corneal-compensated intraocular pressure; CRF, corneal resistance factor; CCT, central corneal thickness; $\mathrm{SE}$, spherical equivalent $\left({ }^{*} p<0.05,{ }^{* * *} p<0.01,{ }^{* * *} p<0.001\right)$.

Table 4. Multiple linear-regression model of the factors associated with corneal resistance factor.

\begin{tabular}{|c|c|c|c|c|}
\hline & Unadjusted (95\% CI, $n=1817)$ & $p$ & Multivariable-adjusted (95\% CI, $n=1591)$ & $p$ \\
\hline Age (years) & $-0.007(-0.012$ to -0.0013$)$ & 0.014 & $0.0012(-0.001$ to 0.002$)$ & 0.08 \\
\hline \multicolumn{5}{|l|}{ Gender } \\
\hline Female & Reference & & Reference & \\
\hline Male & $-0.061(-0.25$ to 0.13$)$ & 0.52 & -0.012 ( -0.06 to 0.03$)$ & 0.61 \\
\hline IOPcc (mmHg) & 0.071 (0.050 to 0.093$)$ & $<0.001^{* * *}$ & 0.295 (0.89 to 0.302$)$ & $<0.001^{* * *}$ \\
\hline $\mathrm{CRF}$ & 0.863 (0.831 to 0.894$)$ & $<0.001^{* * *}$ & 1.18 (1.16 to 1.19$)$ & $<0.001^{* * *}$ \\
\hline CCT & 0.027 (0.025 to 0.029$)$ & $<0.001^{* * * *}$ & 0.001 (0.0005 to 0.0019$)$ & $<0.001^{* * *}$ \\
\hline SE (diopters) & $0.025(-0.0031$ to 0.054$)$ & 0.08 & -0.006 (-0.013 to 0.0009$)$ & 0.09 \\
\hline
\end{tabular}

$R^{2}=0.948$. CRF, corneal resistance factor; IOPcc, corneal-compensated intraocular pressure; CCT, central corneal thickness; SE, spherical equivalent $\left({ }^{* * *} p<0.001\right)$. 


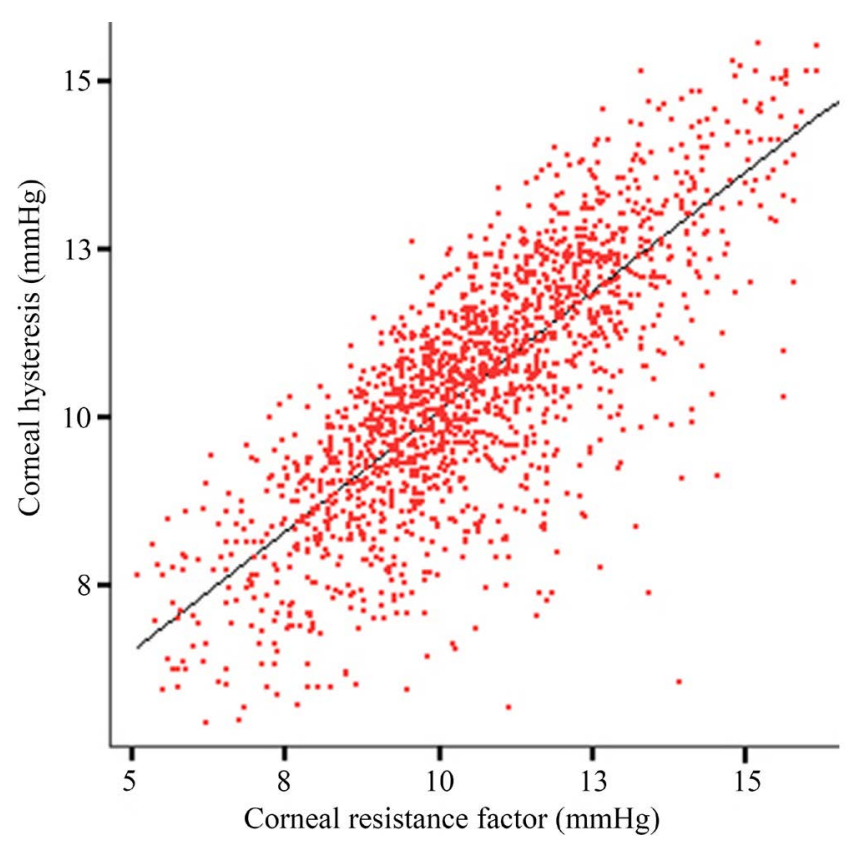

Figure 1. Scatterplot of the relationship between corneal hysteresis and corneal resistance factor. Formula of regression line: $\mathrm{CH}=$ $2.97+0.71 * \mathrm{CRF}, R^{2}=0.61$.

large-scale population-based survey may be required to confirm the relationship between hysteresis and aging in Taiwanese population.

According to the literature, CRF is strongly correlated with CCT in normal subjects [2] [8]. CRF is a corneal biomechanical parameter that is independent of IOP. Factors which affect CCT, such as keratoconus and refractive surgery, cause the CRF to decrease [10] [13]. In addition, the CRF significantly increases with corneal swelling after wearing contact lens with the eyes closed for 3 hours [14]. It remains unclear if the increase in CRF is due to an increase in CCT or an increase in IOP. Although clinical applications of CRF are few, CRF may reflect the integrity of the cornea. Therefore, CRF may be an effective indicator for evaluating interactions between corneal viscoelastic properties and the IOP [15]. CRF was reported in normal subjects as $11.0 \pm 1.6$ mmHg by Kirwan [3], as $10.1 \pm 1.5 \mathrm{mmHg}$ by Kamiya et al. [11] and as $10.1 \pm 1.6 \mathrm{mmHG}$ by Narayanaswamy et al. [12]. In our study, the result was $10.6 \pm 1.99 \mathrm{mmHg}$ which was similar to their findings.

In addition to $\mathrm{CH}$ and CRF, IOPcc is also a new measurement acquired from ORA. In our study, both $\mathrm{CH}$ and CRF were correlated with IOPcc. Furthermore, IOPcc was significantly correlated with CCT. Shen et al. found that the change in IOPcc was related to IOPg, but not to changes in CRF or CH after sleeping. They concluded that IOPcc might exclude some biomechanical effects from the cornea and appears to be "independent" if the increase in IOP is true, but they suggested using an intracameral method for further studies [16]. According to our and other studies, we believed that this discrepancy needs further surveys to explain its meaning and its relationship to IOPcc.

Regarding relationships among these parameters, CH, CRF, and CCT are known to be highly correlated from previous studies [7] [17]. Lim et al. found that $\mathrm{CH}$ and CRF measurements did not vary with age, gender, or race and were also not dependent on the refractive error or axial length [6]. In our survey, relationships of physiologic impact factors including age, gender, and the refractive error with $\mathrm{CH}$ and $\mathrm{CRF}$ were analyzed. However, there was no statistical significance of $\mathrm{CH}$ or CRF with these factors.

This study had some limitations. First, the gender imbalance may impact the statistical power to determine if a difference exists in the corneal biomechanical properties in males and females. Second, we did not exclude patients with a significant systemic illness such as diabetes which might have contributed to the variation in $\mathrm{CH}$ and CRF. Third, corneal problems also influenced hysteresis The selection biases may exist if disease was not diagnosed. Although the population was large enough, these conditions may have influenced the results.

In summary, the relationships of the corneal biomechanical parameters, $\mathrm{CH}$ and CRF, as measured by ORA, 
both showed strong associations with CCT in a healthy Taiwanese (ethnic Chinese) population. A higher CCT was positively correlated with higher $\mathrm{CH}$ and CRF values. The results of this study also indicated that $\mathrm{CH}, \mathrm{CRF}$, and CCT are related but are not computations of the same corneal biomechanical parameter.

\section{Conclusion}

We present basic biomechanical data including $\mathrm{CH}$ and CRF in a large Taiwanese population, and these data do not greatly differ from those of other races and other Asian populations. $\mathrm{CH}$ and CRF measurements did not vary with age, gender, or refraction. Further research on the roles of $\mathrm{CH}$ and the CRF is necessary. Our survey may provide fundamental data in a Taiwanese and Asian population for further studies on corneal biomechanical variations in different diseases.

\section{References}

[1] Chui, W.S., Lam, A., Chen, D. and Chiu, R. (2008) The Influence OF Corneal Properties on Rebound Tonometry. Ophthalmology, 115, 80-84. http://dx.doi.org/10.1016/j.ophtha.2007.03.061

[2] Luce, D.A. (2005) Determining in Vivo Biomechanical Properties of the Cornea with an Ocular Response Analyzer. Journal of Cataract \& Refractive Surgery, 31, 156-162. http://dx.doi.org/10.1016/j.jcrs.2004.10.044

[3] Kirwan, C., O’Malley, D. and O’Keefe, M. (2008) Corneal Hysteresis and Corneal Resistance Factor in Keratoectasia: Findings Using the Reichert Ocular Response Analyzer. Ophthalmologica, 222, 334-337. http://dx.doi.org/10.1159/000145333

[4] Shah, S., Laiquzzaman, M., Cunliffe, I. and Mantry, S. (2006) The Use of the Reichert Ocular Response Analyser to Establish the Relationship between Ocular Hysteresis, Corneal Resistance Factor and Central Corneal Thickness in Normal Eyes. Contact Lens \& Anterior Eye, 29, 257-262. http://dx.doi.org/10.1016/j.clae.2006.09.006

[5] Kirwan, C., O’Keefe, M. and Lanigan, B. (2006) Corneal Hysteresis and Intraocular Pressure Measurement in Children Using the Reichert Ocular Response Analyzer. American Journal of Ophthalmology, 142, 990-992. http://dx.doi.org/10.1016/j.ajo.2006.07.058

[6] Lim, L., Gazzard, G., Chan, Y.H., Fong, A., Kotecha, A., Sim, E.L., et al. (2008) Cornea Biomechanical Characteristics and Their Correlates with Refractive Error in Singaporean Children. Investigative Ophthalmology \& Visual Science, 49, 3852-3857. http://dx.doi.org/10.1167/iovs.07-1670

[7] Elsheikh, A., Wang, D., Rama, P., Campanelli, M. and Garway-Heath, D. (2008) Experimental Assessment of Human Corneal Hysteresis. Current Eye Research, 33, 205-213. http://dx.doi.org/10.1080/02713680701882519

[8] Kotecha, A., Elsheikh, A., Roberts, C.R., Zhu, H. and Garway-Heath, D.F. (2006) Corneal Thickness- and Age-Related Biomechanical Properties of the Cornea Measured with the Ocular Response Analyzer. Investigative Ophthalmology \& Visual Science, 47, 5337-5347. http://dx.doi.org/10.1167/iovs.06-0557

[9] Kirwan, C. and O’Keefe, M. (2008) Corneal Hysteresis Using the Reichert Ocular Response Analyser: Findings Preand Post-LASIK and LASEK. Acta Ophthalmologica, 86, 215-218.

http://dx.doi.org/10.1111/j.1600-0420.2007.01023.x

[10] Ortiz, D., Pinero, D., Shabayek, M.H., Arnalich-Montiel, F. and Alio, J.L. (2007) Corneal Biomechanical Properties in Normal, Post-Laser in Situ Keratomileusis, and Keratoconic Eyes. Journal of Cataract \& Refractive Surgery, 33, 13711375. http://dx.doi.org/10.1016/j.jcrs.2007.04.021

[11] Kamiya, K., Shimizu, K. and Ohmoto, F. (2009) Effect of Aging on Corneal Biomechanical Parameters Using the Ocular Response Analyzer. Journal of Refractive Surgery, 25, 888-893. http://dx.doi.org/10.3928/1081597X-20090917-10

[12] Narayanaswamy, A., Chung, R.S., Wu, R.Y., Park, J., Wong, W.L., Saw, S.M., et al. (2011) Determinants of Corneal Biomechanical Properties in an adult Chinese Population. Ophthalmology, 118, 1253-1259.

[13] Pepose, J.S., Feigenbaum, S.K., Qazi, M.A., Sanderson, J.P. and Roberts, C.J. (2007) Changes in Corneal Biomechanics and Intraocular Pressure Following LASIK Using Static, Dynamic, and Noncontact Tonometry. American Journal of Ophthalmology, 143, 39-47. http://dx.doi.org/10.1016/j.ajo.2006.09.036

[14] Lu, F., Xu, S., Qu, J., Shen, M., Wang, X., Fang, H., et al. (2007) Central Corneal Thickness and Corneal Hysteresis During Corneal Swelling Induced by Contact Lens Wear with Eye Closure. American Journal of Ophthalmology, 143, 616-622. http://dx.doi.org/10.1016/j.ajo.2006.12.031

[15] Jorge, J.M., Gonzalez-Meijome, J.M., Queiros, A., Fernandes, P. and Parafita, M.A. (2008) Correlations between Corneal Biomechanical Properties Measured with the Ocular Response Analyzer and ICare Rebound Tonometry. Journal of Glaucoma, 17, 442-448. http://dx.doi.org/10.1097/IJG.0b013e31815f52b8 
[16] Shen, M., Wang, J., Qu, J., Xu, S., Wang, X., Fang, H., et al. (2008) Diurnal Variation of Ocular Hysteresis, Corneal Thickness, and Intraocular Pressure. Optometry and Vision Science, 85, 1185-1192. http://dx.doi.org/10.1097/OPX.0b013e31818e8abe

[17] Avetisov, S.E., Novikov, I.A., Bubnova, I.A., Antonov, A.A. and Siplivyi, V.I. (2010) Determination of Corneal Elasticity Coefficient Using the ORA Database. Journal of Refractive Surgery, 26, 520-524. 
Scientific Research Publishing (SCIRP) is one of the largest Open Access journal publishers. It is currently publishing more than 200 open access, online, peer-reviewed journals covering a wide range of academic disciplines. SCIRP serves the worldwide academic communities and contributes to the progress and application of science with its publication.

Other selected journals from SCIRP are listed as below. Submit your manuscript to us via either submit@scirp.org or Online Submission Portal.
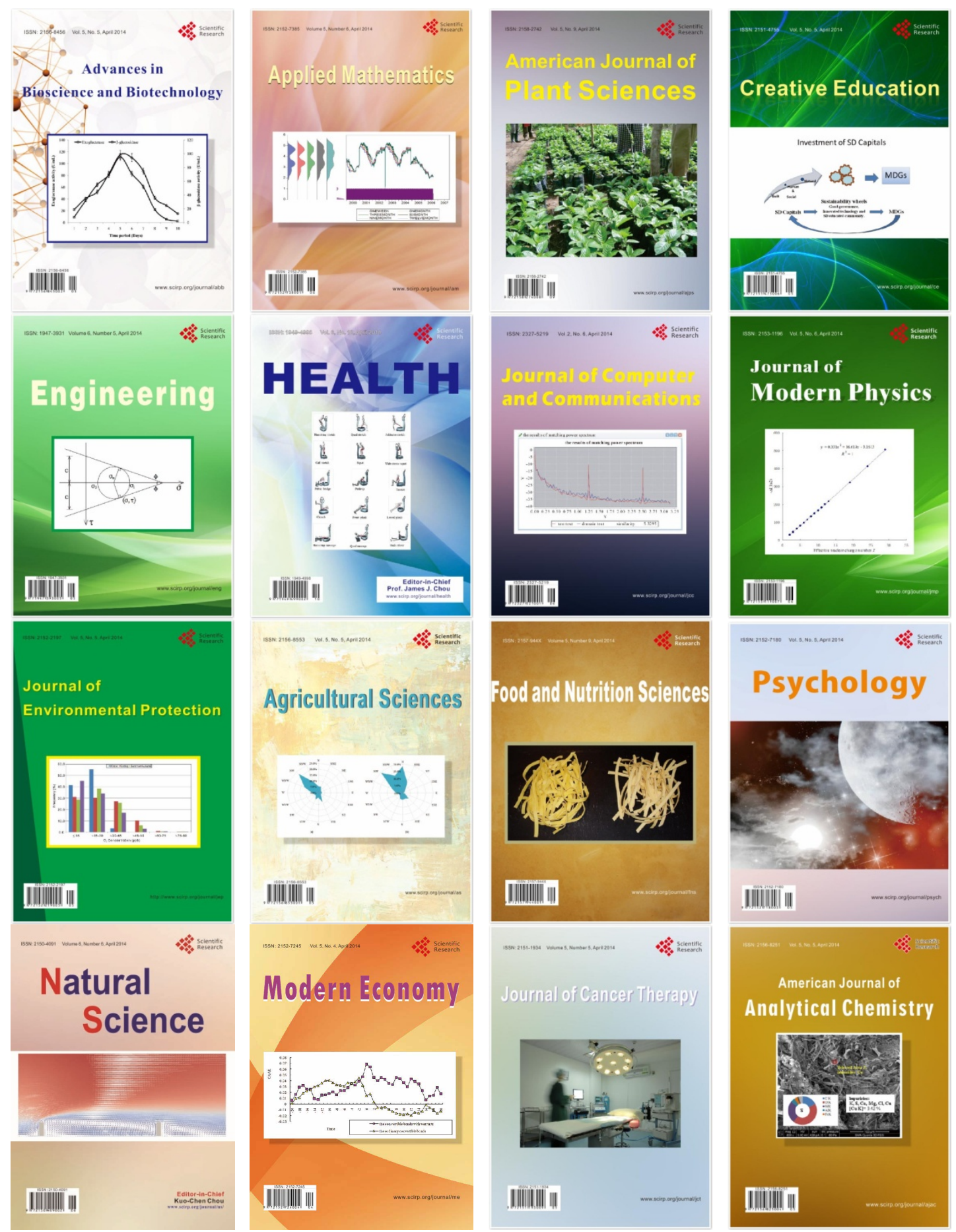